\title{
Homeless with TB? Housing should be part of the treatment, not part of the problem
}

\section{Susan Collinson}

Homerton University Hospital

University College London School of Medicine

\begin{abstract}
Chronic homelessness is a red flag symptom, marking a significantly increased risk of ill-health and premature death in homeless people. By definition homeless people tend to have chaotic and transient lives, as their priorities are very different from housed people. When a homeless person has tuberculosis (TB), and must complete a minimum of six months treatment in order to be cured, adherence to the full course can be an insurmountable problem. For people who are in the United Kingdom (UK) illegally, or with no recourse to public services, the situation is even bleaker. A fear of authority can deter them from seeking health care until the disease is extremely advanced. However, once stabilised on medication and medically fit for discharge from hospital, there is a real danger that they will be lost to follow-up because of their homelessness, thus putting themselves and others at risk. A model for housing homeless TB patients has been developed in Hackney, east London. Those housed have predominantly been in the UK illegally. Having the capacity to house them has made a significant difference to the health of the patient, the work of the TB team, and the cost to local health services.
\end{abstract}

What is known about this topic?

The problem of non-adherence to medical treatment remains a challenge for health professionals. 
- Adherence to tuberculosis treatment is poor in high risk groups such as the homeless

- Incentives have been used to help patients remain on long term treatment (Giuffrida \& Torgerson, 1997; Priebe et al, 2013)

What this paper adds:

- A 'social' problem such as homelessness should be considered as a comorbidity and addressed at the same time as health problems

- Incentives can create conditions for the patient to make other changes to improve overall quality of life

Keywords: Tuberculosis, homelessness, accommodation, health care, service level agreement

\section{Introduction}

"They come singly or in huddled clusters, subdued, their eyes downcast, their shoulders stooped. They tell us tales of loss, of devastation, of living in the shadows, always fearful of exposing themselves to bureaucratic scrutiny. They sleep...in doorways, on park benches, or in churches and bus stations. They are like Dante's lost souls, wafting in limbo..." (de Zulueta, 2011, para. 1).

London is the TB capital of Western Europe. Over the last fifteen years the number of cases in the city has risen by nearly 50 percent (Public Health England, London i, 2014). Rates of TB have stabilised, but the disease remains an urgent public health problem, particularly in hard-to-reach groups. Anybody can get tuberculosis, but some people are more vulnerable because of their circumstances. If you are homeless, you probably have not got straight forward access to health services. If you are a failed asylum seeker, the Court of Appeal has ruled that you may not even have the right to health treatment on the NHS. Treatment for TB differs in that the NHS (Charges for Drugs and Appliances) Regulations 2000 (the Charges Regulations) have now been amended to allow medication for the treatment of tuberculosis to be provided free of charge in TB clinics or via a patient group direction from the $1^{\text {st }}$ September, 2007. 
The London Borough of Hackney (LBH) has one of the largest refugee and asylum seeker populations in London. Many arrive without friends and family, leading to isolation, fear and low confidence (Sheiber, 2006). Although they may be relatively fit on arrival in the UK, there is evidence that their health worsens in the two to three years after arrival. They can meet a number of obstacles in accessing health care systems, for a range of reasons (Palmer \& Ward, 2006):

- Language and cultural differences

- Lack of awareness of how healthcare is delivered in the UK

- Racism

- Failure to prioritise their healthcare compared to other primary needs.

- Stigma in seeking help for TB, because of its close association with HIV

London accounts for 39 percent of the UK TB burden of disease, a rate of 41 per 100,000, and the London Borough of Hackney (LBH) has some of the highest rates within London (Public Health England, London i, 2014; City and Hackney JSNA, 2012). Reasons include global migration, relative deprivation, poor housing stock and overcrowding. The TB team at Hackney's Homerton University Hospital runs a hospital and community-based service for people with TB. The most at-risk groups for catching TB are the homeless, street drinkers, street sex workers, exoffenders, substance misusers, refugee and asylum seekers, and undocumented migrants. Most illegal migrants live 'beneath the radar', working for food, hand-outs or a place to stay. They exist as invisible social outcasts, exploited and fearful.

Evidence demonstrates the importance of providing housing to support treatment completion for TB. Long-term homelessness is fundamentally an issue of health (Bureau of Tuberculosis Control, 2008; Marmot, 2010). Additionally, 'one consequence of the failure to treat and prevent the health outcomes of homelessness is increasing expenditure in secondary care...homeless patients attend [hospital] six times as often as the housed population, are admitted four times as often, and stay twice as long' (Hewett \& Halligan, 2010). The average age of death for homeless people in the UK is between 40 and 44 years old. UK wide, the homeless population generates secondary care costs of $£ 85$ million annually (Hewett \& Halligan, 2010). A Health Protection Agency (HPA) reported that of 6,343 TB cases with known social factors, 2.6 percent 'were currently homeless or had a 
history of homelessness' (Tuberculosis in London, 2010). However, current emergency housing provision does not include TB as a specific priority factor.

Arrangements for housing homeless TB patients in London are extremely ad hoc. Local authorities are reluctant to pay for emergency housing for people with TB. Currently, the economic impact of migrants is a key issue in the public debate on immigration (Dustman \& Frattini, 2013) with a particular focus on 'health tourism'. English local authorities have strict criteria as to who they are legally able to house. In Hackney, the housing department is known as a fierce gate keeper, with five eligibility criteria:

1. Are you homeless?

2. Are you eligible? (Immigration status)

3. Are you in priority need?

4. Are you intentionally homeless?

5. Do you have a local connection?

'Eligibility' addresses the question of immigration status. Criterion five asks for evidence of a local connection within LBH. If the homeless person is an illegal immigrant or visa over stayer, they will have no form of identification and no means of proving when and how they came to the UK, as they tend to destroy these documents.

Homeless TB patients often have quite advanced disease before they seek treatment, while the length of treatment (six months) is very difficult for them to adhere to, not least because many suffer from chronic co-morbidities such as drug and alcohol dependency, BBVs, HIV, and mental illness, difficult to address when the patient is homeless. Every person being treated for TB by the team at Homerton Hospital has an initial risk assessment, and high risk patients are placed on directly observed therapy (DOT), whereby the patient must attend the TB office for their medication. DOT patients are given a monthly bus pass to facilitate attendance. For patients with accommodation, this process works well; for the homeless patient, this arrangement rapidly falls apart, and they become lost to follow up (LFU).

Illegal migrants can be 'over stayers'; people who come in on a time limited visa and then simply stay when the visa runs out, or 'undocumented migrants'; 
people entering the country illegally, sometimes with the assistance of traffickers. These migrants survive by working illegally, and are very vulnerable to exploitation by unscrupulous employers and landlords (sometimes one and the same person), often working long hours for very low or no pay.

All European Union (EU) citizens have the same rights of free movement between countries in the EU. They can enter other member states without a visa for a period of six months and can reside in that country for a longer period if they are employed, self-employed, or otherwise able to support themselves. However, recent accession states from Eastern Europe had restrictions placed upon working in the UK, in the form of the Workers Registration Scheme (WRS), and had to register with an employer, and be employed for twelve months before becoming eligible for state benefits. Data collected from the WRS and the allocation of National Insurance Numbers, show that over 1,000,000 migrants from accession countries have arrived in the UK since 2004; approximately half are thought to have returned to their countries of origin. However, some came to the UK without registering with the WRS, and many have fallen on hard times, becoming homeless and unwell as the recession hit the construction industries. This has placed an additional burden on resources, especially in the inner cities.

The outcomes for homeless TB patients who are ineligible for local authority housing are not good. One is bed blocking, which is unpleasant for ward staff, the patient, and the TB team. Ward staff resent looking after a patient for weeks or even months when he is medically fit for discharge, and kept in hospital for 'social' reasons. The patient senses the feelings of the ward staff. He also gets bored, especially when he has poor English. He will have no visitors, and may abscond from the hospital out of frustration. Once out of hospital, he will almost inevitably drop out of treatment and the disease will reactivate, in which case:

1. He may have to restart treatment from the beginning (if found)

2. He may develop drug resistant TB

3. He may infect $<$ twelve others

4. He may die 
Hospital beds are expensive: “...beds are being blocked by medically-fit people who have nowhere else to go. Around $£ 2 m$ a year is being wasted as patients are forced to stay in hospital beds up to a year longer than needed". [Each bed] "stings the taxpayer an average $£ 400$ per night" (Fenna, 2008, para. 1). However, the cost of 'normal' treatment for TB (from beginning to end without a break) is $£ 5000.00$, set against a possible $£ 50,000$ - $£ 70,000$ for interrupted treatment, when a patient is lost to follow up (LFU), with the further cost implications that their TB can become drug resistant, and there is a high risk of further spread of infection.

In the autumn of 2007, a 47 year old Polish man, living in an underground squat in Hackney, was diagnosed with pulmonary TB, admitted to Homerton Hospital and started on treatment. He spoke almost no English, and felt isolated in his side room. A housing application was made to Hackney's Homeless Person's Unit (HPU). This was turned down, because he had not registered with the WRS, and he became a bed blocker. He became bored and returned to the squat, and for a while he was on DOT. Unfortunately, all the squatters were evicted and scattered, and this patient became LFU. About two months later, he died on the streets of Whitechapel.

This death felt unnecessary and unacceptable. A series of meetings took place between the TB team, the local health commissioners (PCT), and Hackney's HPU with the aim of developing a service level agreement (SLA) to house homeless persons with TB for the duration of treatment. The PCT carried out a cost analysis, looking at hospital admissions for homeless TB patients over three previous years, length of stay in hospital, any re-admissions, and the number who became LFU. These data, combined with information about local costs, (one day in a hospital bed cost more than one week in local authority accommodation) provided the basis for the SLA contract. This provides six housing units per year for homeless patients with TB. Referrals are made by email, and the patient is assessed and housed within 24 to 48 hours. Funding is provided by the local commissioners. The SLA has proved to be cost-effective; it has improved patients' quality of life; and enabled continuity of treatment without break. 
Table 1

Homeless persons with TB housed under the service level agreement (SLA)

\begin{tabular}{|c|c|}
\hline Patient & Outcome \\
\hline 54 year old Lithuanian man and Russian partner & DOT. Completed treatment \\
\hline 47 year old Jamaican man & $\begin{array}{l}\text { DOT. Adherence declined, and he lost his } \\
\text { accommodation. }\end{array}$ \\
\hline 65 year old Albanian man. & DOT. Completed treatment. \\
\hline 21 year man from Guinea-Conakry. & DOT. Completed treatment. \\
\hline 31 year old man from Portugal. & DOT. Completed treatment. \\
\hline $\begin{array}{l}31 \text { year old Ghanaian woman and } 18 \text { month old } \\
\text { daughter. }\end{array}$ & Self-medicated. Completed treatment. \\
\hline ? 21 year old man from Afghanistan. & DOT. Completed treatment. \\
\hline 31 year old woman from Portugal. & DOT. Completed treatment. \\
\hline 30 year old man from Vietnam. & DOT. Completed treatment. \\
\hline 29 year old woman from KwaZulu Natal. & DOT. Completed treatment. \\
\hline 26 year old man from Ghana. & DOT. Completed treatment. \\
\hline 25 year old man from St. Lucia. & DOT. Completed treatment. \\
\hline 35 year old Ghanaian man and pregnant partner. & DOT. Completed treatment. \\
\hline 45 year old Polish man and partner. & DOT. Completed treatment. \\
\hline 44 year old UK woman. & DOT. Completed treatment in hospital. \\
\hline 37 year old British African Caribbean man. & DOT. Completed treatment. \\
\hline 37 year old Ugandan woman. & DOT. Completed treatment. \\
\hline 38 year old British Asian man. & DOT. Completed treatment. \\
\hline 41 year old Nigerian man & DOT. Completed treatment. \\
\hline 53 year old Polish man. & DOT. Completed treatment. \\
\hline $\begin{array}{l}30 \text { year old Nigerian woman and } 19 \text { month old } \\
\text { daughter. }\end{array}$ & DOT. Completed treatment. \\
\hline 56 year old British Asian man. & DOT. Completed treatment. \\
\hline 62 year old man from USA. & DOT. Completed treatment. \\
\hline 53 year old Polish man. & DOT. Completed treatment. \\
\hline 32 year old British Asian man. & DOT. Completed treatment in prison. \\
\hline 41 year old Chinese woman. & DOT. Completed treatment. \\
\hline 27 year old Polish man. & DOT. Adherent. \\
\hline $\begin{array}{l}18 \text { year old man from the Democratic Republic of } \\
\text { Congo. }\end{array}$ & DOT. Completed. \\
\hline $\begin{array}{l}41 \text { year old woman from Eritrea with } 14 \text { year old } \\
\text { daughter. }\end{array}$ & Weekly dossette box. Adherent. \\
\hline 21 year old man from Afghanistan. & DOT. Adherent. \\
\hline 22 year old man from Pakistan. & DOT. Adherent. \\
\hline
\end{tabular}

To date, the SLA has housed 31 patients, from 20 different countries, including the UK. It has transformed our ability to treat homeless people with TB, from diagnosis to completion and cure. The majority have been single and male, though we have also housed two couples, and five single women, two of whom had young children. Five (19 percent) were also HIV positive. Hackney has the fourth highest HIV prevalence rate in London (City and Hackney JSNA, 2012).

\section{Conclusion}

Homelessness is one of the highest risk factors for non-completion of TB treatment. All the patients we have housed have been ineligible according to at least one of the 
five criteria set by LBH. Many of these patients have other complex health and social problems, but housing is the most important factor in maintaining hitherto homeless patients on treatment. A retrospective risk assessment suggests that a majority of the patients we have housed would otherwise have been lost to follow up. An additional benefit of housing homeless patients is that they can then be referred to other health and social care teams. The commissioning of TB services in London is undergoing change, and a pan London TB Control Board has been established. The struggle to house ineligible TB patients is common to all TB services in London. The success of the Homerton SLA reinforces the argument that investing in an accommodation resource on a London-wide basis for homeless TB patients would be both cost effective and humane. As Octavia Hill, the nineteenth century philanthropist and social reformer maintained, "housing equals self-esteem" (Darley, 2012, p. 49). Housing a homeless person for the duration of their TB treatment is an extremely fair strategy. It gives that individual the same chance to become cured as someone who is already housed; it prevents the spread of disease to other vulnerable people; and it gives dignity to the patient.

\section{References}

Bureau of Tuberculosis Control. (2008). Tuberculosis (TB): Clinical Policies and Protocols. New York: New York City Department of Health and Mental Hygiene. Retrieved from http://www.nyc.gov/html/doh/html/tb/tb-manual.shtml

City and Hackney. (2012). City and Hackney health and wellbeing profile (joint strategic needs assessment [JSNA] 2010/11). Retrieved from http://hackney.gov.uk/jsna.htm

Darley, G. (2012). Octavia Hill. In S. Jones (Ed.) The enduring relevance of Octavia Hill (pp. 43-56). London: DEMOS.

de Zulueta, P. (2011). Asylum seekers and undocumented migrants must retain access to primary care. British Medical Journal. 2011;343:d6637 doi: 10.1136/bmj.d6637

Dustmann, C., \& Frattini, T. (2013). The fiscal effects of immigration to the UK. Centre for Research and Analysis of Migration Discussion Paper Series CDP No 22/13. Retrieved from http://www.creammigration.org/publ uploads/CDP 22 13.pdf

Duvell, F. (2006). Irregular migration: A global, historical and economic perspective. In F. Duvell (Ed.), Illegal immigration in Europe: Beyond Control? (pp.60-66). Houndmills: Palgrave/MacMillan.

Fenna, K. (2008). £2m wasted on people blocking hospital beds. North Wales Daily Post. London: Trinity Mirror plc. Retrieved from http://www.thefreelibrary.com/WALES\%3a+pounds+2m+a+year\%3b+N.WAL ES+BED+BLOCKING+SCANDAL+THAT'S+THE...-a0179913400 
Giuffrida, A., \& Torgerson, D. (1997). Should we pay the patient? Review of financial incentives to enhance patient compliance. British Medical Journal, 1997;315:703.

Hewett, N., \& Halligan, A. (2010). Homelessness is a healthcare issue. Journal of the Royal Society of Medicine, 2010:103:306-7. doi: 10.1258/jrsm.2010.10k028

Marmot, M. (2010). Fair society, healthy lives: Strategic review of health inequalities in England, post-2010. London: UCL Institute of Health Equity.

Palmer, D., \& Ward, K. (2006). 'Unheard voices': Listening to refugees and asylum seekers in the planning and delivery of mental health service provision in London. Commission for Patient and Public Involvement in Health. London : CPPIH, 2006 RLRed (Pal). Retrieved from http://www.irr.org.uk/pdf/Unheard Voices.pdf

Priebe, S., Yeeles, K., Bremner, S., Lauber, C., Eldridge, S., Ashby, D., David, A., O'Connell, N., Forrest, A., \& Burns, T. (2013). Effectiveness of financial incentives to improve adherence to maintenance treatment with antipsychotics: Cluster randomised controlled trial. British Medical Journal 2013;347:f5847. doi: 10.1136/bmj.f5847

Public Health England, London i: Tuberculosis. (2014). Communicable disease intelligence for London's health professionals (Number 2014/02). February 2014.

Scheiber, S. (2006). Examining the numbers, locations and employment, training and enterprise needs of London's refugee and asylum seeker communities. London: LORECA Mapping Exercise, London Refugee Action.

Tuberculosis in London. (2010). Annual report on tuberculosis surveillance in London. Health Protection Agency London Regional Epidemiology Unit, August 2011.

\section{Biographical notes}

Susan Collinson has been the TB case worker at Homerton University Hospital NHS Foundation Trust in London for over six years. She also teaches at University College London School of Medicine. She has a PhD in the history of medicine. 